\title{
Über agglutinatorische Veränderungen der Pneumokokken im Tierkörper.
}

\author{
Von \\ Dr. Toru Takami. \\ (高見亨) \\ (Aus dem bakteriologischen Institut der Universität zu Sendai: \\ Direktor, Prof. Dr. K. Aoki.)
}

Die Erscheinung, dass sich pathogene Bakterien im Tierkörper sowohl morphologisch als auch biologisch verändern lassen, wurde schon von vielen Forschern bemerkt. Besonders machte Bail darauf aufmerksam, dass pathogene Bakterien, wemn sie sich im Tierkörper aufgehalten hatten, sich so umändern, dass man sie nicht nur morphologisch, sondern auch biologisch von den originalen Kulturbakterien unterscheiden kann. Dabei nannte er diese im Tierkörper verïnderten Bakterien Animalbakterien. Unter anderen beobachtete Schmitt allerdings, dass sich Paratyphus B-Bazillen, wemn sie mehrmals beim Kalb infiziert worden waren, so verändern lassen, dass sie nicht mehr im Paratyphus B-Serum, sondern im Gärtnerserum gut agglutinabel werden. Er behauptete dabei, dass diese Erscheinung je nach dem Stamme der betreffenden Bakterien und der Individualität des Tierkörpers dabei eine gewisse Rolle spielt. Auf gleiche Weise konnte Jeney nachweisen, dass Paratyphus A-Bazillen nach Mauspassage sich so verändern können, dass sie nicht mehr im homologen Serum agglutinieren können. Mit Streptokokken machte Meyer folgende noch interessantere Beobachtung. Er bereitete zwei Streptokokkenstïmme vor, von denen der eine durch den anderen infolge Tierpassage virulent geworden war. Mit den beiden Stämmen wurden zwei Sera hergestellt. In diesen Sera wurden die beiden Stämme gegenseitig agglutiniert. Es wurde dabei festgestellt, dass der originale Stamm im Serum, welches mit virulentem Stamme hergestellt war, nicht agglutinabel war, und in gleicher Weise virulente Stämme in Serum, welches mit originalem Stamm hergestellt war, nicht mehr agglutinierten. Er meinte dabei, dass die Streptokokken, 
welche direkt aus Menschen genommen waren, im Mauskörper agglutinatorisch ganz andere Typen geworden seien. Bei Pneumokokken machte Huber eine ähnliche Beobachtung. Er konnte mit einem Pneumokokkenstamm, welcher aus Sputum isoliert war, beim Tier so stark wirkende Sera herstellen, dass sie denselben Stamm 1 : 10000 stark agglutinierten. Nach 6 maliger Mauspassage wurde dieser Stamm so verändert, dass er in demselben Serum selbst nicht mehr 1:50 agglutinieren konnte. Dagegen bemerkten Neufeld, Yoshioka, Bürgers u. Herz, dass Pneumokok-

\section{Tabelle 1.}

\begin{tabular}{|c|c|c|c|c|c|}
\hline $\begin{array}{l}\text { Herkunft u. } \\
\text { Eigenschaft. } \\
\text { d. Stämm. } \\
\text { Name } \\
\text { der } \\
\text { Stämme }\end{array}$ & Herkunft & $\begin{array}{l}\text { Aggluti- } \\
\text { nations- } \\
\quad \text { titer }\end{array}$ & $\begin{array}{c}\text { Morpho- } \\
\text { logisches } \\
\text { Verhalten }\end{array}$ & $\begin{array}{c}\text { Verbalten } \\
\text { gegen } \\
\text { Inulin }\end{array}$ & $\begin{array}{c}\text { Verhalten } \\
\text { gegen } \\
\text { Galle }\end{array}$ \\
\hline 86 & $\begin{array}{c}\text { Eiter. } \\
\text { Empyem. pleur. }\end{array}$ & $1: 2.000$ & + & - & + \\
\hline 43 & $\begin{array}{l}\text { Rachenausstrich. } \\
\text { Diphtherie. }\end{array}$ & $n$ & + & + & + \\
\hline 65 & $\begin{array}{l}\text { Rachenausstrich. } \\
\text { Bronchopneumonie. }\end{array}$ & $"$ & + & + & + \\
\hline 67 & $\begin{array}{l}\text { Rachenausstrich. } \\
\text { Meningitis epid. }\end{array}$ & $"$ & + & + & + \\
\hline 80 & $\begin{array}{l}\text { Eiter. } \\
\text { Ulcus serpens. }\end{array}$ & $"$ & + & - & + \\
\hline 107 & $\begin{array}{l}\text { Rachenausstrich. } \\
\text { Branchopneumonie. }\end{array}$ & $"$ & + & + & + \\
\hline 156 & $\begin{array}{l}\text { Cerebrospin. Alussigk. } \\
\text { Meningitis acuta. }\end{array}$ & $"$ & + & + & + \\
\hline 158 & $"$ & $"$ & + & + & + \\
\hline 225 & $\begin{array}{l}\text { Sputum. } \\
\text { Influenzapneumonie. }\end{array}$ & $"$ & + & + & + \\
\hline 236 & $\begin{array}{l}\text { Sputum. } \\
\text { Croup. Pneumonie. }\end{array}$ & $"$ & + & + & + \\
\hline 241 & $\begin{array}{l}\text { Eiter. } \\
\text { Empyem. pleur. }\end{array}$ & $"$ & + & + & + \\
\hline 251 & $\begin{array}{l}\text { Sputum, } \\
\text { Genuin. Pneumonie. }\end{array}$ & $"$ & + & + & + \\
\hline 163 & $\begin{array}{l}\text { Rachenausstrich. } \\
\text { Bronchopneumonie. }\end{array}$ & " & + & + & + \\
\hline 209 & $\begin{array}{c}\text { Sputum. } \\
\text { Genuin. Pneumonie. }\end{array}$ & $"$ & + & - & + \\
\hline 220 & $\begin{array}{c}\text { Eiter. } \\
\text { Empyem. pleur. }\end{array}$ & $"$ & + & -- & - \\
\hline 233 & $\begin{array}{l}\text { Sputum. } \\
\text { Influenzapneumonie. }\end{array}$ & $"$ & + & + & + \\
\hline 239 & $\begin{array}{c}\text { Eiter. } \\
\text { Fmpyem. pleur. }\end{array}$ & $"$ & + & + & + \\
\hline 263 & $\begin{array}{l}\text { Rachenausstrich. } \\
\text { Angina. }\end{array}$ & $"$ & + & + & + \\
\hline
\end{tabular}


ken, welche avirulent geworden waren, im homologen Serum nicht mehr agglutinieren. Falls sie aber durch Tierpassage virulent gemacht worden waren, so konnten sie sich wieder so verändern, dass sie in demselben Serum ebenso gut wie vorher agglutinieren konnten.

Wie schon von mir mitgeteilt, zeigten Pneumokokken auf Blutagar sowohl morphologisch als auch kulturell Variationen, wenn sie lange Zeit auf künstlichen Nährböden umgezüchtet gehalten wurden. Gleiches Verhalten zeigten sie agglutinatorisch. Dabei wurde festgestellt, dass kulturelle und morphologische Variation mit agglutinatorischer Variation keinen Zusammenhang hat. Nun wurde untersucht, wie sie sich im Tierkörper variieren würden. $Z u$ diesem $Z$ wecke wurde mit 18 Stämmen Tierpassage bei Mäusen durchgeführt, welche nicht nur typisch kulturellen morphologischen Charakter, sondern auch so starke Agglutinabilität in homologen Sera, wie 1:2000, zeigten (Tab. 1). Diese Stämme waren avirulent, weil sie lange Zeit auf Blutagar gehalten worden waren. Dabei wurde festgestellt, dass die Agglutinabilität dieser Stämme in homolgen Sera immer abnahm. Die Abnahme ging bei manchen Stämmen schliesslich so weit, dass sie selbst nicht mehr 1:50 stark agglutinieren konnten, wie schon Huber beobachtete. Dabei wurde erkannt, dass die Herabsetzung der Agglutinabilität von den Stämmen abhängig ist. So war sie bei einem Stamme schon durch die erste Tierpassage so weit fortgeschritten, dass er selbst 1:50 nicht agglutinieren konnte. Fünf andere Stämme wurden nach der 3 . Tierpassage, 2 weitere Stämme erst nach der 6 . noch 3 andere Stämme erst nach 7 maliger und der letzte eine Stamm erst nach 10 maliger Tierpassage inagglutinabel. Dagegen konnte ich bei den übrigen 6 Stämmen keine Herabsetzung der Agglutinabilität, selbst nach 10 maliger Tierpassage nachweisen (Tab. 2). Die gleiche Erscheinung wurde auch bei denselben Pneumokokkenstïmmen durch andere Tierpassage nachgewiesen, wie Kaninchen-, Meerschweinchen-, weisse Ratten- oder Hausrattenpassage ('Tab. 3). Woran dürfte diese Herabsetzung der Agglutinabilität liegen, welche durch Tierpassieren hervorgerufen wurde? Da wir schon bei der Herabsetzung der Agglutinabilität der Pneumokokken auf Blutagar eine Variationserscheinung erlebten, welche darin bestand, dass dabei schwächer als der Titer agglutinierende Kolonien neu gebildet wurden, so zerlegten wir solche Stämme in Kolonien, welche durch die Tierpassage noch nicht ganz inagglutinabel geworden waren. Dabei wurden neben inagglutinablen Kolonien noch solche nachgewiesen, welche noch ziemlich stark agglutinierbar sind. Falls dagegen solche Stämme in Kolonien zerlegt wurden, welche selbst nicht mehr 1:50 agglutinieren 
Tabelle 2.

\begin{tabular}{|c|c|c|c|}
\hline \multirow[b]{2}{*}{$\begin{array}{l}\text { Name } \\
\text { der Stïmme }\end{array}$} & \multicolumn{2}{|c|}{ Titer der Agglutination } & \multirow{2}{*}{$\begin{array}{c}\text { Mal der } \\
\text { Tierpassage (Maus) }\end{array}$} \\
\hline & $\begin{array}{l}\text { Vor der } \\
\text { Tierpassage }\end{array}$ & $\begin{array}{c}\text { Nach der } \\
\text { Tierpassage }\end{array}$ & \\
\hline $\begin{array}{r}36 \\
43 \\
65 \\
67 \\
80 \\
107 \\
156 \\
158 \\
225 \\
236 \\
241 \\
251 \\
163 \\
209 \\
220 \\
233 \\
239 \\
263\end{array}$ & $\begin{array}{c}1: 2,000 \\
" \\
" \\
" \\
" \\
" \\
, \\
" \\
" \\
" \\
" \\
" \\
" \\
" \\
"\end{array}$ & $\begin{array}{c}1: 50- \\
", \\
" \\
" \\
", \\
", \\
" \\
", \\
", \\
1: 2,000 \\
", \\
" \\
" \\
" \\
"\end{array}$ & $\begin{array}{r}1 \\
10 \\
7 \\
3 \\
7 \\
3 \\
3 \\
3 \\
6 \\
7 \\
3 \\
6 \\
10 \\
" \\
, \\
, \\
, \\
"\end{array}$ \\
\hline
\end{tabular}

Tabelle 3.

\begin{tabular}{|c|c|c|c|}
\hline \multirow{2}{*}{$\begin{array}{l}\text { Agglutinationstiter } \\
\text { und } \\
\text { Passagetiere }\end{array}$} & \multicolumn{2}{|c|}{ Titer der Agglutination } & \multirow[b]{2}{*}{ Passagetiere } \\
\hline & $\begin{array}{c}\text { Vor der } \\
\text { Tierpassage }\end{array}$ & $\begin{array}{l}\text { Nach der } \\
\text { Tierpassage }\end{array}$ & \\
\hline $\begin{array}{l}158 \\
, " \\
"\end{array}$ & $\begin{array}{c}1: 2,000 \\
, " \\
",\end{array}$ & $\begin{array}{c}1: 50- \\
, \\
" \\
"\end{array}$ & $\begin{array}{l}\text { Kaninchen. } \\
\text { Meerschweinchen. } \\
\text { Weise Ratte. } \\
\text { Graue Ratte. }\end{array}$ \\
\hline
\end{tabular}

können, so wurden keine Kolonien mehr nachgewiesen, die noch agglutinabel weren (Tab. 4). Nach diesem Ergebnis kann man wohl annehmen, die Erscheinung, dass Pneumokokken durch 'Tierpassage inagglutinabel werden, sei dadurch zustande gekommen, dass solche Varianten im Tierkörper entweder plötzlich oder allmählich neu gebildet werden, die im originalen Serum nicht mehr agglutinieren können. Nun fragt es sich, ob diese schweragglutinablen Mikroben diejenigen sind, welche durch Ver- 
Tabelle

\begin{tabular}{|c|c|c|c|c|c|c|c|c|c|}
\hline $\begin{array}{l}\text { Name } \\
\text { der } \\
\text { Passagestämme }\end{array}$ & & 1 & 2 & 3 & 4 & 5 & 6 & 7 & 8 \\
\hline 43 IX Pass.-st. & 43 & $\begin{array}{l}50- \\
50-\end{array}$ & $\begin{array}{r}1,000 \\
50-\end{array}$ & $\begin{array}{l}50- \\
50-\end{array}$ & $\begin{array}{l}50- \\
50-\end{array}$ & $\begin{array}{l}50- \\
50-\end{array}$ & $\begin{array}{l}50- \\
50-\end{array}$ & $\begin{array}{l}100 \\
50-\end{array}$ & $\begin{array}{l}100 \\
50-\end{array}$ \\
\hline $\begin{array}{l}\text { V Pass.-st. } \\
\text { VII Pass-st. }\end{array}$ & 65 & $\begin{array}{l}100 \\
50-\end{array}$ & $\begin{array}{l}50- \\
50-\end{array}$ & $\begin{array}{l}100 \\
50-\end{array}$ & $\begin{array}{l}100 \\
50-\end{array}$ & $\begin{array}{l}50- \\
50-\end{array}$ & $\begin{array}{l}50- \\
50-\end{array}$ & $\begin{array}{l}50- \\
50-\end{array}$ & $\begin{array}{l}50- \\
50-\end{array}$ \\
\hline $\begin{array}{l}\text { VI Pass.-st. } \\
80 \text { VIII Pass.-st. }\end{array}$ & so & $\begin{array}{l}50- \\
50-\end{array}$ & $\begin{array}{l}100 \\
50\end{array}$ & $\begin{array}{l}100 \\
50-\end{array}$ & $\begin{array}{l}100 \\
50-\end{array}$ & $\begin{array}{l}100 \\
50-\end{array}$ & $\begin{array}{l}50 \\
50-\end{array}$ & $\begin{array}{l}50- \\
50-\end{array}$ & $\begin{array}{l}200 \\
50-\end{array}$ \\
\hline $\begin{array}{l}225 \text { IV Pass.-st. } \\
\text { VII Pass.-st. }\end{array}$ & 225 & $\begin{array}{l}100 \\
50-\end{array}$ & $\begin{array}{l}100 \\
50-\end{array}$ & $\begin{array}{l}50 \\
50-\end{array}$ & $\begin{array}{l}50- \\
50-\end{array}$ & $\begin{array}{l}50- \\
50-\end{array}$ & $\begin{array}{l}50 \\
50-\end{array}$ & $\begin{array}{l}200 \\
50-\end{array}$ & $\begin{array}{l}200 \\
50-\end{array}$ \\
\hline 236 V Pass.-st. & 236 & $\begin{array}{l}500 \\
50-\end{array}$ & $\begin{array}{l}500 \\
50-\end{array}$ & $\begin{array}{l}50 \\
50-\end{array}$ & $\begin{array}{l}50- \\
50-\end{array}$ & $\begin{array}{l}50- \\
50-\end{array}$ & $\begin{array}{l}100 \\
50-\end{array}$ & $\begin{array}{l}100 \\
50-\end{array}$ & $\begin{array}{l}100 \\
50-\end{array}$ \\
\hline 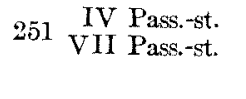 & 251 & $\begin{array}{l}500 \\
50-\end{array}$ & $\begin{array}{l}500 \\
50-\end{array}$ & $\begin{array}{l}500 \\
50-\end{array}$ & $\begin{array}{l}200 \\
50-\end{array}$ & $\begin{array}{c}1,000 \\
50-\end{array}$ & $\begin{array}{l}500 \\
50-\end{array}$ & $\begin{array}{l}500 \\
50-\end{array}$ & $\begin{array}{l}200 \\
50-\end{array}$ \\
\hline
\end{tabular}

lust ihrer Rezeptoren einfach schwer agglutinabel wurden, oder ob sie diejenigen darstellen, welche dadurch schwer agglutinabel wurden, dass neue selbständige Rezeptoren im Tierkörper entstanden. Um diese Frage zu entscheiden, wurden Tiere mit diesen Kulturen vorbehandelt, welche durch Tierpassage so inagglutinabel geworden waren, dass man durch Plattenverfahren darin keine agglutinierende Kolonie mehr nachweisen konnte. Dabei wurden die Passagestämme sorgfältigst rein gehalten. Tiere wurden im ganzen in 7 tägigen Intervallen mit steigenden Dosen 6 mal vorbehandelt. Wie man aus der Tabelle (Tab. 5) leicht ersehen kann, zeigte es sich, dass man mit schwer agglutinablen Stämmen ganz leicht bei Kaninchen solche Sera erzeugen kann, welche im Originalserum schweragglutiuable Passagestämme 1:2 000 stark agglutinieren können. Nach diesem Resultat scheint letztere Annahme ganz zutreffend zu sein. Wie verhalten sich aber orginale Stämme diesem Passagestammserum gegenüber? Sie wurden sowohl im Originalserum als auch im Variantenserum 
4.

\begin{tabular}{|c|c|c|c|c|c|c|c|c|c|c|c|}
\hline 9 & 10 & 11 & 12 & 13 & 14 & 15 & 16 & 17 & 18 & 19 & 20 \\
\hline $\begin{array}{l}100 \\
50-\end{array}$ & $\begin{array}{r}1,000 \\
50-\end{array}$ & $\begin{array}{l}100 \\
50-\end{array}$ & $\begin{array}{l}50- \\
50-\end{array}$ & $\begin{array}{l}50- \\
50-\end{array}$ & $\begin{array}{l}50- \\
50-\end{array}$ & $\begin{array}{l}50- \\
50-\end{array}$ & $\begin{array}{l}50- \\
50-\end{array}$ & $\begin{array}{l}50- \\
50-\end{array}$ & $\begin{array}{l}200 \\
50-\end{array}$ & $\begin{array}{l}200 \\
50-\end{array}$ & $\begin{array}{l}100 \\
50-\end{array}$ \\
\hline $\begin{array}{l}50- \\
50-\end{array}$ & $\begin{array}{l}100 \\
50-\end{array}$ & $\begin{array}{l}500 \\
50\end{array}$ & $\begin{array}{l}500 \\
50-\end{array}$ & $\begin{array}{l}50- \\
50-\end{array}$ & $\begin{array}{l}50- \\
50-\end{array}$ & $\begin{array}{l}50- \\
50-\end{array}$ & $\begin{array}{l}50- \\
50-\end{array}$ & $\begin{array}{l}50- \\
50-\end{array}$ & $\begin{array}{l}50- \\
50-\end{array}$ & $\begin{array}{l}50- \\
50-\end{array}$ & $\begin{array}{l}100 \\
50-\end{array}$ \\
\hline $\begin{array}{l}100 \\
50-\end{array}$ & $\begin{array}{l}50- \\
50-\end{array}$ & $\begin{array}{l}50- \\
50-\end{array}$ & $\begin{array}{l}100 \\
50-\end{array}$ & $\begin{array}{l}100 \\
50-\end{array}$ & $\begin{array}{l}50- \\
50-\end{array}$ & $\begin{array}{l}50- \\
50-\end{array}$ & $\begin{array}{l}50- \\
50-\end{array}$ & $\begin{array}{l}50- \\
50-\end{array}$ & $\begin{array}{l}50- \\
50-\end{array}$ & $\begin{array}{l}50- \\
50-\end{array}$ & $\begin{array}{l}50- \\
50-\end{array}$ \\
\hline $\begin{array}{l}100 \\
50-\end{array}$ & $\begin{array}{l}100 \\
50-\end{array}$ & $\begin{array}{l}50 \\
50-\end{array}$ & $\begin{array}{l}50 \\
50-\end{array}$ & $\begin{array}{l}50 \\
50-\end{array}$ & $\begin{array}{l}50 \\
50-\end{array}$ & $\begin{array}{l}500 \\
50-\end{array}$ & $\begin{array}{l}200 \\
50-\end{array}$ & $\begin{array}{l}200 \\
50-\end{array}$ & $\begin{array}{l}50 \\
50-\end{array}$ & $\begin{array}{l}50 \\
50-\end{array}$ & $\begin{array}{l}50 \\
50-\end{array}$ \\
\hline $\begin{array}{l}50 \\
50-\end{array}$ & $\begin{array}{l}500 \\
50-\end{array}$ & $\begin{array}{l}50- \\
50-\end{array}$ & $\begin{array}{l}50- \\
50-\end{array}$ & $\begin{array}{l}50- \\
50-\end{array}$ & $\begin{array}{l}50- \\
50-\end{array}$ & $\begin{array}{l}50- \\
50-\end{array}$ & $\begin{array}{l}50- \\
50-\end{array}$ & $\begin{array}{l}200 \\
50-\end{array}$ & $\begin{array}{l}50- \\
50-\end{array}$ & $\begin{array}{l}500 \\
50-\end{array}$ & $\begin{array}{l}100 \\
50-\end{array}$ \\
\hline $\begin{array}{r}1,000 \\
50-\end{array}$ & $\begin{array}{l}500 \\
50-\end{array}$ & $\begin{array}{l}200 \\
50-\end{array}$ & $\begin{array}{l}500 \\
50-\end{array}$ & $\begin{array}{l}500 \\
50-\end{array}$ & $\begin{array}{l}500 \\
50-\end{array}$ & $\begin{array}{l}200 \\
50-\end{array}$ & $\begin{array}{l}500 \\
50-\end{array}$ & $\begin{array}{l}500 \\
50-\end{array}$ & $\begin{array}{l}500 \\
50-\end{array}$ & $\begin{array}{r}1,000 \\
50-\end{array}$ & $\begin{array}{l}500 \\
50-\end{array}$ \\
\hline
\end{tabular}

agglutiniert. Dabei ergab sich, dass viel Originalstämme in Variantenserum ebensogut wie in Originalserum agglutinieren konnten; aber drei Stämme waren in Variantenserum nicht imstande zu agglutinieren. (Tab. 6). Nach diesem Versuchsresultate scheint es gerechtfertigt, anzunehmen, dass Pneumokokken, welche sich lange Zeit im Tierkörper aufgehalten hatten, sich agglutinatorisch so verändern lassen, dass sie selbständige neue Rezeptoren bekommen. Die drei letzteren Stämme müssten diese Annahme bestätigen. Die übrigen Stämme, welche diese Annahme nicht ganz zu beweisen scheinen, müssten so beschaffen gewesen sein, dass sie sich auf Blutagarnährboden noch nicht genügend umgewandelt haben und deshalb den betreffenden Passagestämmen noch verwandtschaftlich nahe stehen. Falls sie aber noch längere Zeit auf Blutagar gehalten und sich weiter hätten verändern lassen, so könnten sie auch in Variantenserum nicht mehr agglutinieren. Nach allen obigen Versuchen kann man sicherlich annehmen, dass sich Pneumokokken im Tierkörper ebenso var- 
Tabelle 5 .

\begin{tabular}{|c|c|c|c|c|c|c|c|c|c|c|}
\hline \multirow{2}{*}{ 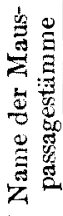 } & \multicolumn{2}{|c|}{ I } & \multicolumn{2}{|c|}{ II } & \multicolumn{2}{|r|}{ III } & \multicolumn{2}{|r|}{ IV } & \multicolumn{2}{|r|}{$\mathrm{V}$} \\
\hline & s. c. & $\begin{array}{l}\text { Blut- } \\
\text { probe }\end{array}$ & i. $\nabla$. & $\begin{array}{l}\text { Blut- } \\
\text { probe }\end{array}$ & i. $v$. & $\begin{array}{l}\text { Blut- } \\
\text { probe }\end{array}$ & i. $\nabla$. & $\begin{array}{l}\text { Blut- } \\
\text { probe }\end{array}$ & i. $\nabla$. & $\begin{array}{l}\text { Blut- } \\
\text { probe }\end{array}$ \\
\hline 36 & 3 e.c. & - & 3.5 c.c. & - & 4 c.c. & $1: 500$ & 4.5 c.c. & $1: 1,000$ & 5 c.c. & $1: 2,000$ \\
\hline 43 & $n$ & - & $"$ & - & $"$ & $1: 200$ & $n$ & $1: 1,000$ & $n$ & $1: 2,000$ \\
\hline 65 & $"$ & - & $"$ & - & $n$ & $1: 500$ & " & $1: 1,000$ & $"$ & $1: 2,000$ \\
\hline 67 & $"$ & - & $"$ & - & $"$ & $1: 500$ & $"$ & $1: 1,000$ & $"$ & $1: 2,000$ \\
\hline 80 & $"$ & - & $"$ & - & " & $1: 500$ & $"$ & I $: 1,000$ & $"$ & $1: 2,000$ \\
\hline 107 & $"$ & - & $"$ & - & $"$ & $1: 500 \pm$ & $"$ & $1: 1,000$ & $"$ & I : 2,000 \\
\hline 156 & $"$ & \pm & $"$ & - & $"$ & $1: 1,000$ & $"$ & $1: 2,000 \pm$ & $"$ & $1: 2,000$ \\
\hline 158 & $"$ & - & $"$ & - & $"$ & $1: 500$ & $"$ & $1: 1,000$ & $"$ & $1: 2,000$ \\
\hline 225 & $"$ & - & $"$ & - & $"$ & $1: 500$ & $"$ & $1: 1,000$ & $"$ & $1: 2,000$ \\
\hline 236 & $"$ & - & $"$ & - & $"$ & $1: 500$ & $"$ & $1: 1,000$ & $"$ & $1: 2,000$ \\
\hline 241 & $"$ & - & $"$ & - & $"$ & $1: 500$ & $"$ & $1: 1,000$ & $"$ & $1: 2,000$ \\
\hline 251 & $"$ & - & $"$ & - & $"$ & $1: 500$ & $"$ & $1: 1,000$ & $"$ & $1: 2,000$ \\
\hline
\end{tabular}

Tabelle

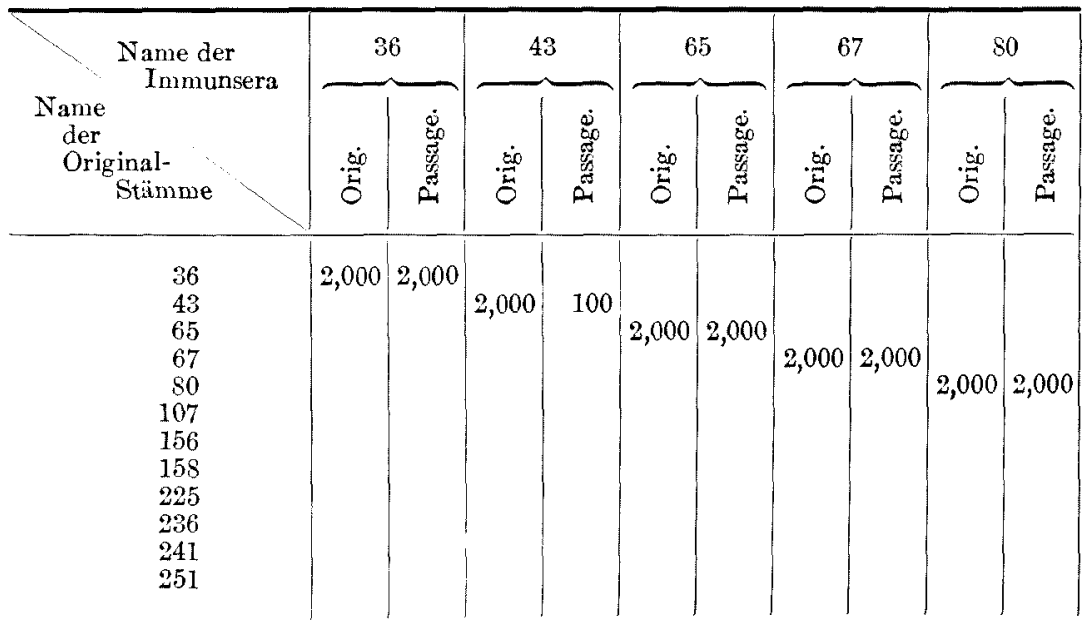


lieren, wie auf künstlichem Nährboden. Diese Varianten scheinen im Tierkörper einfacher als auf Nährböden zu sein. Ferner muss bemerkt werden, dass die Varianten, welche im 'Tierkörper gebildet waren, von den anderen, welche auf Nährböden neu gebildet wareu, agglutinatorisch verschieden sind. Infolgedessen glaube ich, dass sich Pneumokokken, lange Zeit auf künstlichem Nährmedium gehalten, dabei so verändern können, dass sie ihre originalen Rezeptoren verlieren, dagegen andere nene Rezeptoren bekommen. Falls diese Mikroben lange Zeit in Tierkörper versetzt gehalten werden, so könnèn sie sich wieder so umwandeln, dass sie im Tierkörper statt alter Rezeptoren andere neue bekommen und im originalen Serum nicht mehr agglutinieren können. Im Hinblick hierauf möchte ich diejenigen Pneumokokken, welche sich auf künstlichem Nährboden so haben verändern lassen, dass sie andere neue agglutinatorische Rezeptoren bekommen, Kulturbakterien, dagegen jene Pneumokokken, welche, durch Tierpassage wieder aus Kulturbakterien verändert, andere neue agglutinatorische Rezeptoren erhalten, Animalbakterien nennen, wie schon Bail sie nannte. Dabei sprach er aber nicht über agglutinatorische Eigenschaften. Nun wird es bald klar, dass die Beobachtung von Neufeld und Händel, Yoshioka, Bürgers und Herz, dass Pneumokokken, welche schwer agglutinabel geworden, wieder agglutinabel werden, falls sie durch Tierkörperpassage wieder virulent geworden sind, zu Hubers ebenso wie zu meiner eigenen Beobachtung, dass Pneumokokken, welche in homologen Seren gut agglutinabel waren, bald schwer oder inagglu-

6.

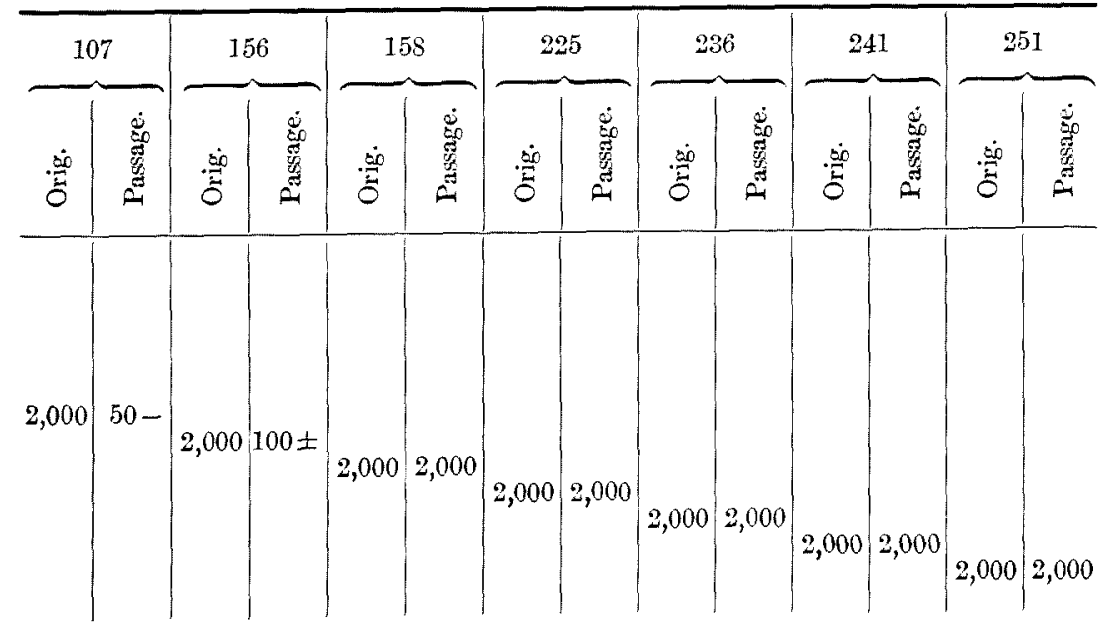


tinabel werden, falls sie im Tierkörper gehalten werden, in gar keinem Widerspruch steht. Der Unterschied besteht nämlich nur darin, dass sie mit virulenten Animalbakterien, wir dagegen mit avirulenten Kulturbakterien von Pneumokokken zu arbeiten angefangen hatten. Obigem Ergebnis möchte ich noch eine andere interessante Beobachtung hinzufügen. Wenn obige Annahme immer zutreffend wäre, so kann man weiter erwarten, dass schwer agglutinable Kolonien, welche aus typischen gut agglutinierbaren Kulturbakterien isoliert waren, im Gegensatze zu den anderen gut agglutinablen Kolonien gegen Tiere virulent sein werden. Um diese Annahme zu beweisen, wurden folgende Versuche ausgeführt: 5 typische Staimme von Kulturbakterien wurden durch Plattenverfahren in Kolonien zerlegt. Einzelne Kolonien wurden in originalem Serum agglutinatorisch untersucht. Dabei wurden zweierlei Kolonien festgestellt, die eine leicht und die andere schwer oder inagglutinabel. Diese beiden Kolonien wurden Mäusen intraperitoneal eingespritzt. Wie aus der Tabelle ersichtlich, zeigten bei allen Stämmen ohne Ausnahme diejenigen Kolonien starke Virulenz, welche schwer agglutinabel waren, dagegen die nicht, welche in homologem Serum gut agglutinabel waren ('Tab. 7). Dabei muss bemerkt werden, dass schwer agglutinable Kolonien, welche starke Virulenz gezeigt hatten, immer solche typischen Kolonien waren, welche die in der früheren Mitteilung genau beschriebenen Eigenschaften vollkommen behielten. Nach diesem Ergebnis scheint meine obige Annahme tatsächlich erwiesen zu sein. Nun fragt es sich, ob diese auf künstlichem Nährboden schwer agglutinablen, dabei aber virulenten Kolonien, wie andere schwer agglutinablen, durch Tierpassage zustande gekommenen Kulturen im Tierkörper als Antigen so wirken können, dass sie reichliche Neubildung von Agglutinin hervorrufen. Aus äusseren Gründen wurden diese Versuche leider hier nicht besonders angestellt. Doch scheint ein anderer Versuch, welcher in einer anderen Mitteilung beschrieben wurde, zu beweisen, dass man mit diesen schwer agglutinablen Kulturen bei Tieren agglutinierende Sera nicht erzeugen kann. Deswegen muss die Sache wohl so vor sich gehen, dass die schwer agglutinablen Kolonien erst als Antigen wirksam werden können, falls sie einmal den Tierkörper passiert haben, weil ich an anderer Stelle eine gleichfalls in diesem Sinne aufufassende Erscheinung beobachtete, dass nämlich Kulturpneumokokkentämme nach Tierpassage eine ganz andere gegenseitige agglutinatorische Bezichung zeigten, obwohl ihre Virulenz vor und nach der Tierpassage gar nicht verändert worden waren. Diese Erscheinung wird in der nächsten Mitteilung genau auseinandergesetzt werden. Falls diese Annahme richtig ist, so kann man 
Tabelle 7.

\begin{tabular}{|c|c|c|c|c|c|}
\hline 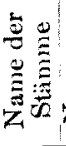 & 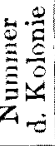 & 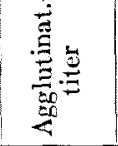 & Tierfersuch & \multicolumn{2}{|c|}{ Resultat } \\
\hline 225 & $\begin{array}{r}2 \\
30 \\
5 \\
24\end{array}$ & 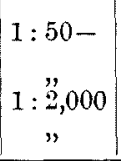 & $\begin{array}{c}0.5 \mathrm{ccm} .20 \text { stdig. } \\
\text { Bouillonkultur. Maus i.p. } \\
", \\
",\end{array}$ & $\begin{array}{l}\text { n. } 24 \text { St. Agonal } \\
\text { n. } 24 \text { St. Gesund } \\
"\end{array}$ & $\begin{array}{l}\text { n. } 2 \text { Tag. + p.c. }(+) \\
\text { n. } 4 \text { Tag. Gesnnd } \\
\text { ", }\end{array}$ \\
\hline 241 & $\begin{array}{r}3 \\
13 \\
23 \\
5 \\
10 \\
17\end{array}$ & $\begin{array}{rl}1: & 50- \\
& " \\
1 & : \\
2,000 & " \\
& "\end{array}$ & $\begin{array}{c}0.5 \mathrm{~cm} .20 \text { stdig. } \\
\text { Bouillonkultur. Maus i.p. } \\
", \\
" \\
" \\
"\end{array}$ & $\begin{array}{c}\text { n. } 24 \text { St. +p.c. (+) } \\
\text { n. } 24 \text { St. Gesund } \\
", \\
\end{array}$ & $\begin{array}{c}\text { n. } 4 \text { Tag. Gesund } \\
", \\
\end{array}$ \\
\hline 258 & $\begin{array}{r}1 \\
9 \\
13 \\
15 \\
6 \\
8 \\
12 \\
17\end{array}$ & $\begin{array}{c}1: 50- \\
", \\
1: " 2,000 \\
", \\
",\end{array}$ & $\begin{array}{c}0.5 \mathrm{ccm} .20 \text { stdig. } \\
\text { Bouillonkultur. Maus i.p. } \\
\text { " } \\
" \\
" \\
" \\
" \\
"\end{array}$ & $\begin{array}{c}\text { n. } 24 \text { St. Agonal } \\
", \\
\text { n. } 24 \text { St. Gesund } \\
", \\
",\end{array}$ & $\begin{array}{c}\text { n. } 2 \text { Tag. +p.c. }(+) \\
\text { ", } \\
\text { n. } 3 \text { Tag. Gesund } \\
\text { ", } \\
\text { ", }\end{array}$ \\
\hline 280 & $\begin{array}{r}20 \\
21 \\
2 \\
4 \\
13\end{array}$ & $\begin{array}{c}1: 50- \\
, " \\
1: \stackrel{2,000}{\prime \prime} \\
, "\end{array}$ & $\begin{array}{c}0.5 \mathrm{ccm} .20 \text { stdig. } \\
\text { Bouillonkultur. Maus i.p. } \\
", \\
" \\
" \\
"\end{array}$ & $\begin{array}{c}\text { n. } 24 \text { St. }+ \text { p.c. }(+) \\
\text { ", } \\
\text { n. } 24 \text { St. Gesund } \\
", \\
",\end{array}$ & $\begin{array}{c}\text { n. } 3 \text { Tag. Gesund } \\
",\end{array}$ \\
\hline 248 & $\begin{array}{r}3 \\
5 \\
8 \\
11 \\
6 \\
9 \\
13 \\
14\end{array}$ & $\begin{array}{c}1: 50- \\
", \\
1: \\
1: 2,000 \\
", \\
",\end{array}$ & $\begin{array}{c}0.5 \mathrm{cem} .20 \text { stdig. } \\
\text { Bouillonkultur. Maus i.p. } \\
\text { " } \\
", \\
", \\
\text { ", } \\
\text { ", }\end{array}$ & $\begin{array}{c}\text { n. } 24 \text { St. Agonal } \\
", \\
\text { n. } 24 \text { St. Gesund } \\
" \\
"\end{array}$ & $\begin{array}{c}\text { n. } 2 \text { Tag. + p.c. }(+) \\
", \\
\text { n. } 4 \text { Tag. Gesund } \\
" \\
"\end{array}$ \\
\hline
\end{tabular}

erklären, dass Virulenz der Mikroben und agglutinatorische Rezeptoren in keinem direkten Zusammenhang stehen. Sie können vielmehr ganz voneinander getrennt vorhanden sein. Ich möchte ferner noch eine andere Erfahrung hinzufügen, welche diese Annahme beweisen dürfte. Drei stark virulente Stämme wurden auf Blutagar über 20mal umgezüchtet. Auf diese Weise wurde ihre Virulenz bis zur Hälfte herabgesetzt. Doch blieb ihre Agglutinablität ganz unverändert, also wie vor der Umzüchtung. 
Sie blieben nämlich immer schwer agglutinabel. Huber, welcher dieselbe Erfahrung gemacht hatte, war auch der Meinung, dass agglutinatorische Rezeptoren und Virulenz der Mikroben nicht direkt zusammenhängen.

Zum Schluss sei hinzugefügt, dass die Variationsbildung je nach der Tierspezies auch verschieden gestaltet vorzukommen scheint, weil Meyer schon beobachtete, dass das Serum, welches einen durch Tierpassage virulent gewordenen Stamm darstellte, den Originalmenschenstamm nicht mehr beeinflussen kann, dagegen das Serum, welches mit Originalstamm hergestellt war, den Passagestamm nicht mehr agglutiniert. Auch ich konnte eine ähnliche Erscheinung bei einem Stamm beobachten. Ein typischer Stamm wurde Mans, Kaninchen, Meerschweinchen, weisser Ratte und grauer Ratte so eingespritzt, so dass die Tiere dadurch zugrunde gingen. Mit den aus den einzelnen Tieren gezüchteten Stämmen wurden Sera bei Kaninchen hergestellt, welche in homologen Stämmen so stark wie $1: 2,000$ agglutinieren können. In diesen Sera wurden die ihnen entsprechenden 5 Stämme kreuzweise agglutiniert. Es ergab sich, dass einzelne Passagestämme nicht mehr gegenseitig gleich stark reagieren konnten, so dass man annehmen darf, dass die einzelnen Passagestämme voneinander verschieden sind (Tab. 8). Falls stets alles so, wie oben

Tabelle 8 .

\begin{tabular}{|c|c|c|c|c|c|}
\hline $\begin{array}{l}\text { Name der } \\
\text { Immunsera } \\
\text { Name der } \\
\text { Bakterien }\end{array}$ & $\begin{array}{l}\text { Maus. } \\
\text { Pass.-S. }\end{array}$ & $\begin{array}{l}\text { Kan. } \\
\text { Pass. }-\mathrm{S} .\end{array}$ & $\begin{array}{l}\text { Meerschw. } \\
\text { Pass.-S. }\end{array}$ & $\begin{array}{l}\text { Grau. } \mathrm{R} . \\
\text { Pass.-S. }\end{array}$ & $\begin{array}{l}\text { Weiss. } \mathrm{R} . \\
\text { Pass. } \mathrm{S} \text {. }\end{array}$ \\
\hline $\begin{array}{l}\text { Maus. Passagestamm } \\
158\end{array}$ & 1,000 & 1,000 & 1,000 & 1,000 & 1,000 \\
\hline Kaninch. Passagestanim & $100-$ & 1,000 & 1,000 & 1,000 & $100-$ \\
\hline $\begin{array}{c}\text { Meerschw. Passagestamm } \\
158\end{array}$ & 100 & 1,000 & 1,000 & 1,000 & 100 \\
\hline Graue Ratt. Passagestanm & 1,000 & 1,000 & 1,000 & 1,000 & 100 \\
\hline $\begin{array}{l}\text { Weisse Ratt. Passagestanm } \\
158\end{array}$ & 100 & 1,000 & 1,000 & 1,000 & 1,000 \\
\hline
\end{tabular}

auseinandergesetzt wurde, verlaufen sollte, so müsste man immer daran denken, wie man sowohl bei der Darstellung von Impfstoffen und Immunsera als auch bei der agglutinatorischen Einteilung der Stämme der Pneumokokken darauf Rücksicht zu nehmen habe. 


\section{Literatur.}

B a il, Centralbl. f. Bakt., I. Abt. Orig., 1907, 43, 641.

Schmitt, Centralbl. f. Bakt., I. Abt. Ref., 1912, 51, 17.

Jeney, Centralbl. f. Bakt., I. Abt. Orig., 1923, 91, 366.

Meyer, Deutsch. Med. Wochenschr., 1902, 751.

Huber, Berl. klin. Wochenschr., 1903, 358.

Neufeld, Zeitschr. f. Hyg., 1902, 40, 54.

Yoshiok a, Zeitsch. f. Hyg., 1923, 97, 232.

B iirgers u. Herz, Centralbl. f. Bakt. I. Abt. Orig., 1923, 91, 42.

Tak am i, Tohoku J. Exp. Med., 1925, 6, 41, 65. 